\title{
Mapping Psychological \& Sociological Influences on Individual Decision Making and Brand Choices
}

\author{
Ray Titus, Bhavika Veeramachaneni \\ Alliance School of Business, Alliance University, Bangalore, India \\ E-mail address: ray.titus@alliance.edu.in, vbhavika@bus.alliance.edu.in
}

Keywords: Consumer; Decision Making; Psyche; Socio-cultural environment

\begin{abstract}
Understanding and responding to the quintessential customer is the only way marketers will survive high density competition in the market place. Giving the consumer what he needs, when he needs it and where he needs it is the key to smart marketing. Providing consumer solutions in turn require marketers to know their target consumers' psyche and the sociological influences that bear down on them. This research study uses multiple qualitative tools like personality tests, perception tests, in depth interviews and projective techniques to understand the psyche, social cultural environment and the decision making framework of an individual research subject. The subject chosen for the single individual case study was a student at an MBA program in the metropolitan city of Bangalore. He is in his mid-20s looking to move on to a corporate job after the completion of graduate business program. The research primarily focussed on understanding the influences his social circumstances and his personal psyche had on consumption decision making.
\end{abstract}

\section{INTRODUCTION}

In this age of dynamic content and cluttered market space along with intense cut-throat competition, it has become inevitable to understand the consumer, his exact needs and his desires. Thus, a smart marketer will strive to have complete understanding about the consumer's psyche his personality, his sources of motivation, what motivates him and how he is motivated, his perception about the world he lives in, the way he learns, the attitude and behaviour he exhibits in the marketing arena. In order to understand these, it most important to understand the influences that affect him and how deeply they affect him. When a marketeer has a profound understanding of these aspects about the consumer, understanding the consumer's decision making process and criteria for decision making becomes much easier. All of this information attained becomes a catalyst for the marketeer to build a marketing plan apt for the consumer. This means the marketeer can offer and position the product in a way that the consumer desires, the promote the product in places where the consumer is active and most responsive, deliver it in the right size, place and time and price is exactly where the consumer is willing to buy it.

A longitudinal study has been conducted on subject to understand the psyche, the sociocultural influences and the decision making framework. The subject for this study is J, a student at an MBA program at a leading University based in Bangalore, India. He is a Christian from the state of Kerala, but most of his upbringing was outside of Kerala. Currently his family is settled in Muscat, Oman. He has a key interest in starting his own entrepreneurial venture in a couple of years.

\section{LITERATURE REVIEW}

For the marketer, the consumer who is in the end an individual is viewed seeking solutions to his need and wants. Understanding consumers is in effect deciphering how individuals and groups select, purchase, and dispose of products, services, ideas, or experiences aimed at satisfying needs and desires (Solomon, 1995; Stayman \& Deshpande, 1989). The sum total of what makes up the purchase activity is amenable to varying degrees of marketer influence (Foxall, 1987). In defining consumption behaviour it has been stated as, "Those acts of individuals directly involved in obtaining, using, and disposing of economic goods and services, including the decision processes 
that precede and determine these acts" (Engel, Kollat, \& Miniard, 1986). However it is important to note is still only a particular component in larger engagement that is the consumer experience (Holbrook \& Hirschman, 1982).

For the consumer the act of decision making commences when an exposure to stimuli, internal of external gets him to admit to his needs and wants (Hawkins, Best, \& Coney, 1998). The consumer bring into play both his internal psyche and external social-cultural influences when he considers a purchase decision. Thus it can be said that the values and beliefs the consumer imbibes from the outside combined with his motives, perceptions, and attitudes influence his consumption decision making (Engel, Blackwell, \& Kollat, 1978; Fishbein \& Ajzen, 1975).

\section{RESEARCH METHODOLOGY}

A comprehensive set of tools and technique have been used to carry out the longitudinal study. At the initial stages of the study, a few personality tests were conducted. Personality tests such as Myer Briggs Type Indicator (MBTI), Big 5 Traits, Open Four Temperament Scales (O4TS) \& Narcissistic Personality Inventory (NPI) and DISC (Dominance, Influence, Steadiness and Compliance) test were taken. After this personality test, Thematic Apperception Test (TAT), Rorschach Inkblot Test and few picture-drawing activities were conducted. The major tools used in this research were in-depth formal and informal interviews combined with laddering and projective techniques. Some of the aspects of the interviews also revolved around products and lifestyle choices. MBTI as a tool is designed to measure the psychological preferences in how people perceive and make decisions. The Big 5 traits questionnaire helped in understanding the five broad dimensions of personality. O4TS is related to the four humours based on the following terms sanguine, choleric, melancholic and phlegmatic. NPI is used to evaluate the narcissistic quotient in the subject. DISC test helps in behavioural assessment which is centred on four different behavioural traits.

\section{FINDINGS \& ANALYSIS}

The data of the in-depth interviews has been analysed while keeping in mind the results of the various tests that were taken. A narrative approach has been used to explain the analysis.

$\mathrm{J}$ is the third and the youngest child in his family. He has two siblings - an older brother and an older sister. Being the youngest child, in his childhood he was an extremely pampered child and the apple of his mother's eyes. He spent most of his childhood in Kerala until he was 8; post which his family moved to Muscat. He came to India to pursue his secondary education. He joined the Army school for his Grade XI and XII in Nasik. He believes, 'he joined the army school to become disciplined' but only later in the analysis it was revealed that discipline was imbibed into him at a much younger age. Post grade XII, he pursued BSc in Mathematics in the city of Pune for a year and then realised it wasn't his cup of tea. He then tried to join the Indian Army with two unsuccessful attempts - only to realise something different was in store for him. That is when he came upon the opportunity to a undergraduate business program in Pune where his mother and sister were living. From then on he has never 'looked back'; $J$ is now pursuing a graduate degree in business from a leading business school based at Bangalore in the field of marketing.

When J was given the task of drawing (Appendix A) his family, friends, college and his classroom; he divided the paper given into four exact pieces - saying he believes these are the four most important facets of his life. After the drawing activity many questions related to the picture he drew were asked to understand the reasons behind his drawings. J stated, 'Family and friends are the emotional side of me as compared to the college and classroom which are mere means of reaching my end goal.' Thus even in the pictures it can be seen that family and friends have been drawn in dark strokes and much better page usage as compared to college and class. Considering each of the parts of the drawing task that was given - in the family he drew all his family members in blue and himself in orange. He feels he is the odd one out in the matter of ideologies about religion, culture and its norms and values, marriage and spirituality. Thus to prove the rebellion, he drew himself in a different colour. He is very open to other cultures; he has even visited a temple - while many in 
his extended family believe it to be anti-religious. While he believes God is a creator, and what we create of our lives is rather in our own hands than in God's hands. While on the contrary, he drew two of his best friends with interconnected hands - showing the intimacy and loyalty they share by drawing them all in the same colour. He also added the word - friends 'forever' to this piece to reiterate that he only makes small group of friends but those are the one he wants to have for over a lifetime. He is willing to go out of his way to help them out and he feels they will do the same.

Here some of the personality traits from the test are evident - when he is slightly introverted and only opens up to his friends. He also says that he only gets along with people who have his mind set - people who are extremely space giving and open minded to opinions. He also drew a burger saying food is the way to connect with friend. It the one thing that he loves - to share food with his friends and that is the current key interest he has. He has also visited up to 30 restaurants in Bangalore after joining the business graduate program. He is very open for trials - be it food or culture or regions or places. On the other side he drew the classroom - where he respects the professor's knowledge and experiences and he believes in long term learning happen only when the professor is able to relate to the mind-set of the student in class. He says, 'there have been many professors who have great amounts of knowledge - but they fail to transfer that to students'.

The college is merely a road to reach his end goal of becoming an entrepreneur. While summarizing the activity certain key facts were revealed. $J$ has always looked up to his father as a person who has achieved a lot in a short period of time - at a very young age he was exposed to his father and mother's lifestyle. He recollects both his parents being extremely clean and organized and same is the class with him today. He decided to choose the business route in his career as he has seen his father grow. J's current hobby is reading books and staying updated in technology, marketing, news and start-ups. These are similar traits which his sister had imbibed into him at the young age of 8 , when she introduced the Harry Potter series to him at the age of 9 . He has spent most of his childhood away from his brother; therefore his brother hasn't influenced him much. Although when they meet over the summer breaks they have a great deal of fun being active outside the home both of them being outdoorsy. He says, 'We have broken our backs over roller skating'. Thus, even today $\mathrm{J}$ leads an active lifestyle. His love for foods comes purely from his family. $\mathrm{J}$ is 'Malayali' by ethnicity, who believes he is an Indian at heart. He doesn't abide by the cultural norms of the society and there have been many instances in the in-depth interviews where this view point has come up.

Having comprehended J's background and social cultural environment with the use of some elements how his personality formed, the research now takes a much more marketing focussed view. Given a list of products to describe, $J$ has the knack for rationalizing and logically thinking about the options he has. But to understand this better, our research focuses on the elements of his psyche. The Thematic Apperception Test (TAT) is carried out to do a personality assessment. TAT was carried out on the given picture (Appendix B). J was given a task to write a 10 minutes observational summary for the picture and the things he related to. Based on the write-up his personality was analysed. J described the picture give thus,

Nisha is a young ambitious girl pursuing her B.Sc Chemistry in

Pune. She was inspired to do this course as she was an avid fan of

Marie curie from childhood and she loved chemistry. Her chemistry professor, Ms. Sudha encouraged her passion as she saw potential in Nisha's works. Nisha had enrolled for the National paper presentation as she wanted to present her findings to a wider audience which will be a stepping stone to enter her passion of pure research in chemistry. Miss. Sudha is helping her in the lab to provide support for her theoretical claims. On the day of the paper presentation competition even though Nisha felt light-hearted and nervous she gave her best and when the results came, she couldn't believe her ears. She had won the first position and also got an opportunity to work with acclaimed chemists.

Based on the write-up the following analysis was derived using Linguistic Inquiry and Word Count (LIWC). 
Table 1: LIWC Analysis Scores

\begin{tabular}{|l|c|c|}
\hline \multicolumn{1}{|c|}{ LIWC Dimension } & J's Scores & Male Average \\
\hline Need for Achievement & 6.34 & 5.8 \\
\hline Need for Affiliation & 0.70 & 1.1 \\
\hline Need for Power & 2.11 & 1.7 \\
\hline Self-References (I, Me, My) & 0.00 & 0.5 \\
\hline Social Words & 14.08 & $1 . .4$ \\
\hline Positive Emotions & 5.63 & 1.8 \\
\hline Negative Emotions & 0.70 & 1.5 \\
\hline Big Words (>6 letters) & 27.46 & 18.7 \\
\hline
\end{tabular}

The analysis scores show $\mathrm{J}$ has a high need for achievement, because this output typically elicits themes associated with achievement, most people don't pay too much attention to human relationships in their story - thus a lower score on affiliation. The need for power is reinforced across many tests which were also shown in the DISC (Dominance, Inducement, Submission, and Compliance) test; where dominance is highly prominent as seen below. Even in the DISC, J scored low on compliance.

Table 2: DISC Test Scores

\begin{tabular}{|l|c|}
\hline \multicolumn{1}{|c|}{ DISC Factor } & J's Scores (\%) \\
\hline Dominance & 53 \\
\hline Steadiness & 16 \\
\hline Compliance & 20 \\
\hline Influence & 12 \\
\hline
\end{tabular}

This is further complemented by the Narcissistic Personality Inventory as seen below. Due to the dominance being prominent, he is high on authority and superiority which is again coupled with the low score on compliance.

Table 3: Narcisstic Personality Inventory

\begin{tabular}{|l|c|}
\hline \multicolumn{1}{|c|}{ Personality Trait } & Score \\
\hline Authority & 5 \\
\hline Self-Sufficiency & 5 \\
\hline Superiority & 5 \\
\hline Exhibitionism & 4 \\
\hline Exploitativeness & 2.5 \\
\hline Vanity & 3 \\
\hline Entitlement & 5 \\
\hline
\end{tabular}

To add further depth to similar personality characteristics and traits the O4TS test proves it again. Domination is again very evident from the choleric temperament. He likes to be in charge of everything, with high organization skills. The test output characterised J as 'choleric'. Such a temperament is fundamentally ambitious and leader-like. It has been found that people with choleric temperaments are aggressive, energetic, and even passionate. What's more, they try and instil such an enthusiasm in the people they engage with. Choleric people also have the tendency to dominate others, trying to be in charge of most affairs. Though cholerics are to prone to being assertive they are also subject to mood-swings and at times fall into deep and sudden depression. 
Table 4: The Big 5 Traits Scores

\begin{tabular}{|l|c|c|}
\hline \multicolumn{1}{|c|}{ Trait } & Score & Percentile \\
\hline Extraversion & 3.9 & 78 \\
\hline Conscientiousness & 3.5 & 52 \\
\hline Neuroticism & 1.7 & 7 \\
\hline Agreeableness & 4 & 51 \\
\hline Openness & 4 & 42 \\
\hline
\end{tabular}

On the Big 5 Traits, J scores low on agreeableness and openness which further proves the point that he wants things done his way and he will go out of the way to have it done. This will help the marketer in building products specific to his psychological needs. He also scores low on conscientiousness. While he scores high on extraversion in Big 5 traits, he is preferred to be an introvert in the MBTI.

Table 5: Myers Briggs Type Indicator Scores

\begin{tabular}{|l|c|}
\hline \multicolumn{1}{|c|}{ MBTI Indicator } & J's Scores (\%) \\
\hline Introvert & 22 \\
\hline Intuitive & 12 \\
\hline Feeling & 38 \\
\hline Perceiving & 11 \\
\hline
\end{tabular}

While $\mathrm{J}$ believes he is a highly rational decision maker, the MBTI states he has moderate preference towards feelings than thinking and perceiving rather than judging. This is proven again when the in-depth interview about various products is conducted.

$\mathrm{J}$ is given a list of lifestyle products, FMCG products and services to discuss upon which the laddering technique is used. In the case of car, J owns a Renault duster - where he gradually shifts his attitude towards a Duster from being a stylish car to a car that proves his dominance on the road. It scares away the smaller car. So is the case with his perfume Davidoff Cool Water, which is long lasting and fresh - but most importantly its subtle flavour is what appeals to him. He started purchasing the product as a result of his father's usage of the same perfume. The exact similar description is given by him when asked about his cologne after shave lotion. He uses what his dad prescribes to and chooses the musk flavour. In terms of a clothing, he was asked about ties and he believes in dressing for the occasion, but he doesn't mind being retro when it comes to wedding. He believes it makes him stand out of the crowd. Many of his personality traits discussed about are prominent in the choice of his lifestyle products.

On the other hand, the opposite is true for FMCG products; these are mere attribute based purchases such as Sensodyne is used by him for his sensitive teeth, Unibic cookies as they are filling and Fruit Unibic cookies as they have his favourite raisins. The shoe polish is useful as long as it shines the shoe and nothing else matters. For services he has a different perspective, currently he is on a budgeted monthly income - thus loves to eat out at places that give him a filling meal with a great variety and ambience. If the food was bad, nothing else would matter anymore. He would never visit the place again, wouldn't even give it a second chance. While making restaurant decisions, $\mathrm{J}$ is a great believer of the voice of the consumer - therefore he would check all the reviews of the restaurant and especially the low rated reviews and take an intuitive call on the trail of that restaurant.

Thus he is extremely active help seeker on Zomato.com. While on an e-commerce site, he displays similar traits and reads the reviews before making a decision about the product he is willing to buy. The flight service - an economically priced one would be preferred but is strongly against Air India after the experiencing the turbulence inside the flight. These examples display the way he learns about brands and forms attitude towards them depending on which category they exist in. 


\section{CONCLUSION}

Based on the analysis and research conducted on $\mathrm{J}$ it has been clearly established that his personal psychological makeup and influences he has been subject to in his sociocultural environment are key determinants of the decision behaviour, including those relevant to consumption. It can also be conclude that a combination of the two is the prime influence in his consumption behaviour. Thus it can be said that understanding consumer behaviour is an inevitable requirement for smart marketers. The power of understanding the consumer is the competitive advantage the brands of the today and the future have. They must leverage on this opportunity to capture the mind-set of their most valuable asset - the consumer.

\section{APPENDIX}

Appendix A: Picture Drawing

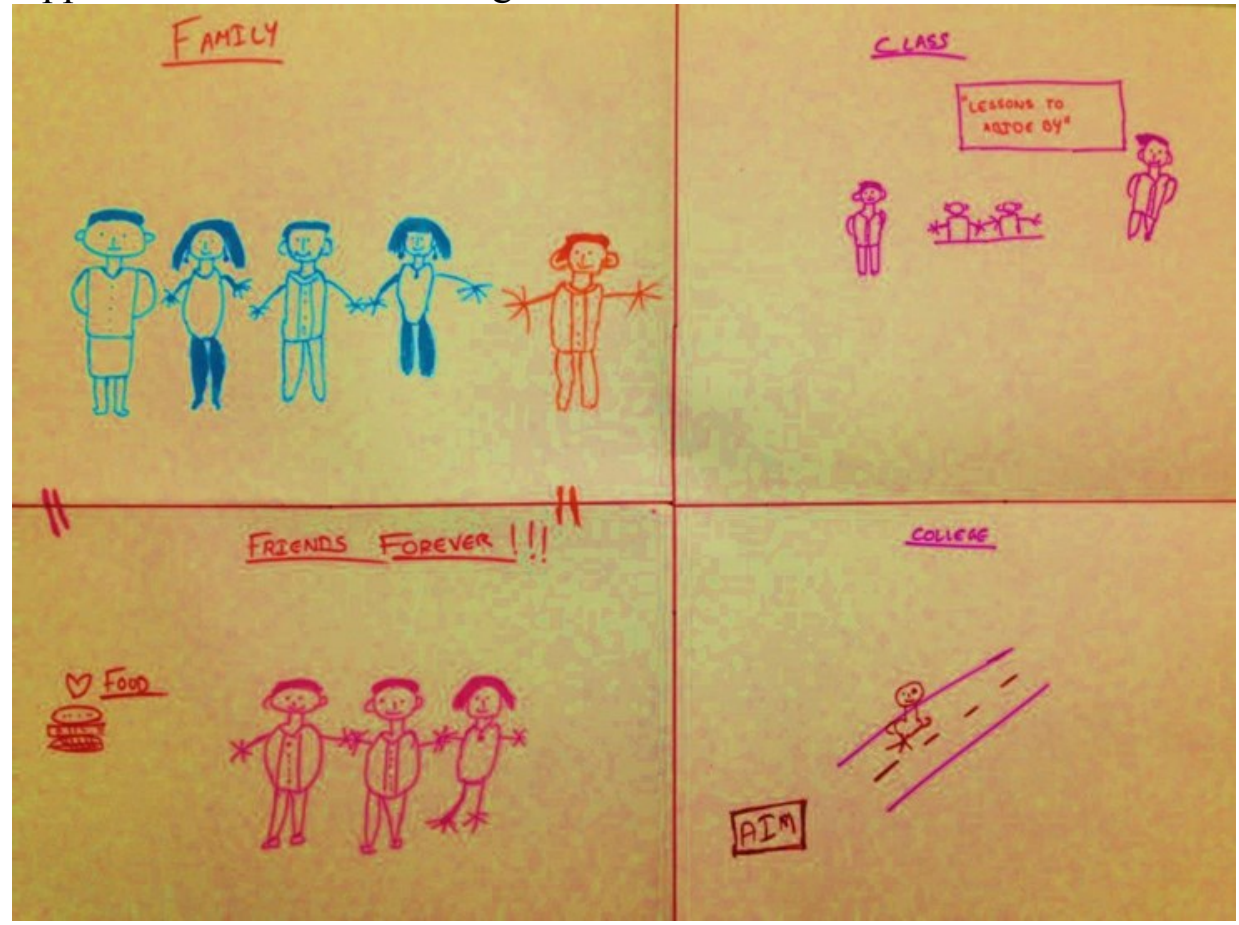

Appendix B: TAT Picture

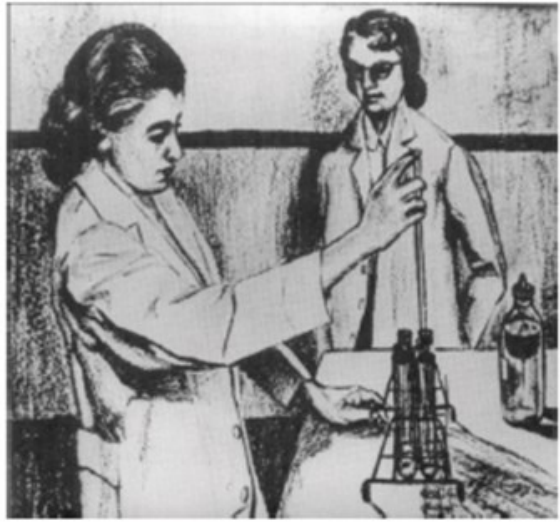




\section{References}

[1] Engel, J. F., Blackwell, R. D., \& Kollat, D. T. (1978). Consumer Behavior. Hinsdale, IL: Dryden Press.

[2] Engel, J., Kollat, R., \& Miniard, P. (1986). Consumer Behavior (5 ed.). Hinsdale, Ill.: Dryden Press.

[3] Fishbein, M., \& Ajzen, I. (1975). Belief, Attitude, Intention, and Behavior: An Introduction to Theory and Research. Reading, MA. : Addison-Wesley.

[4] Foxall, G. R. (1987). Radical Behaviorism and Consumer Choice. International Journal of Research in Marketing(4 ), 111-129.

[5] Hawkins, I., Best, R. J., \& Coney, K. A. (1998). Consumer behavior: Building marketing strategy. New York: Irwin/McGraw-Hill.

[6] Holbrook, M. B., \& Hirschman, E. C. (1982, Septembe 9). The Experiential Aspects of Consumption: Consumer Fantasies, Feelings, and Fun. Journal of Consumer Research, 132140.

[7] Solomon, M. (1995). Consumer Behaviour (3 ed.). Prentice Hall.

[8] Stayman, D. M., \& Deshpande, R. (1989, December). Situational Ethnicity and Consumer Behaviour. Journal of Consumer Research, 16, 361-371. 